\title{
Refined Analysis of Fatigue Crack Initiation Life of Beam-to-Column Welded Connections of Steel Frame under Strong Earthquake
}

\author{
Weilian Qu, Ernian Zhao, and Qiang Zhou \\ Hubei Key Laboratory of Roadway Bridge and Structure Engineering, Wuhan University of Technology, Wuhan, Hubei 430070, China \\ Correspondence should be addressed to Weilian Qu; quweilian_wh@126.com
}

Received 11 August 2017; Revised 13 November 2017; Accepted 15 November 2017; Published 17 December 2017

Academic Editor: Tai Thai

Copyright (c) 2017 Weilian Qu et al. This is an open access article distributed under the Creative Commons Attribution License, which permits unrestricted use, distribution, and reproduction in any medium, provided the original work is properly cited.

\begin{abstract}
This paper presents a refined analysis for evaluating low-cycle fatigue crack initiation life of welded beam-to-column connections of steel frame structures under strong earthquake excitation. To consider different length scales between typical beam and column components as well as a few crucial beam-to-column welded connections, a multiscale finite element (FE) model having three different length scales is formulated. The model can accurately analyze the inelastic seismic response of a steel frame and then obtain in detail elastoplastic stress and strain field near the welded zone of the connections. It is found that the welded zone is subjected to multiaxial nonproportional loading during strong ground motion and the elastoplastic stress-strain field of the welded zone is three-dimensional. Then, using the correlation of the Fatemi-Socie (FS) parameter versus fatigue life obtained by the experimental crack initiation fatigue data of the structural steel weldment subjected to multiaxial loading, the refined evaluation approach of fatigue crack initiation life is developed based on the equivalent plastic strain at fatigue critical position of beam end seams of crucial welded connections when the steel frame is subjected to the strong earthquake excitation.
\end{abstract}

\section{Introduction}

The brittle fracture of traditional beam-to-column welded connections of steel frames is one of the most major causes for the failure of the steel structures under strong earthquake excitation. Seismic damage investigations after the Northridge and Kobe earthquakes show that fatigue crack initiation and propagation at or near the welded connections may cause serious seismic damage, which can endanger the safety of steel frame structures and even cause the collapse of steel frame structures $[1,2]$. The typical fracture of beam-tocolumn welded connections caused by earthquakes is shown in Figure 1.

The fatigue cracks may initiate at the weld of the bottom flange of the beams near the connection, or sometimes at the weld of the top flange [3-5]. In addition, the fatigue cracks may propagate to the column flange or the beam web and finally cause the fracture of welded beam-to-column connections [3-5]. The seismic damage of the welded beam-tocolumn connections is commonly considered to be caused by the low-cycle fatigue subjected to plastic strain and the insufficient ability of the welded material against fracture. Because the fracture usually initiates at or near the welds, to investigate the fatigue crack initiation and propagation of the welded connections, it is essential to focus on the simulation of local stress and strain fields near the weld details of the beam-to-column connections.

The current studies on fatigue damage of beam-tocolumn welded connections are commonly based on the global seismic response at the ends of columns and beams of a steel frame structure, and the hysteretic characteristics between the internal forces and the displacement at the ends of component are used to assess the fatigue life of connections. Krawinkler and Zohrei [6] described the relationship between the plastic strain range and the number of cycles prior to fracture by using the Manson-Coffin equation and seismic inelastic response and then predicted fatigue damage life of the welded connection based on a linear damage accumulation law. Bernuzzi et al. [7] proposed a formula of the $S-N$ curve for the crack initiation and fatigue life of 


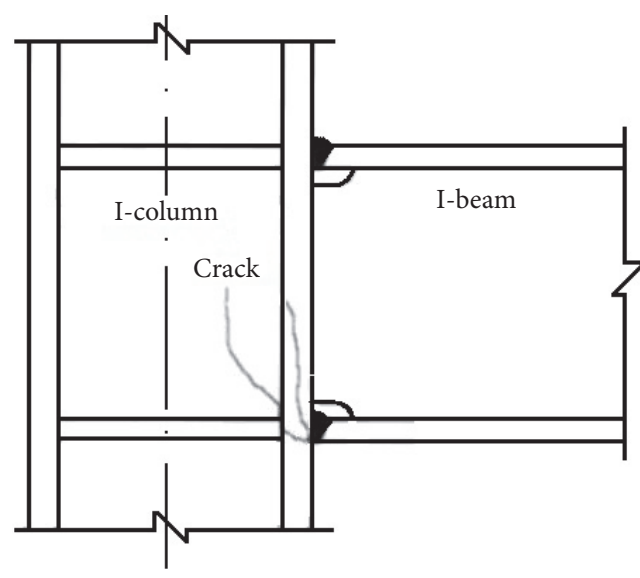

(a) I-beam to I-column

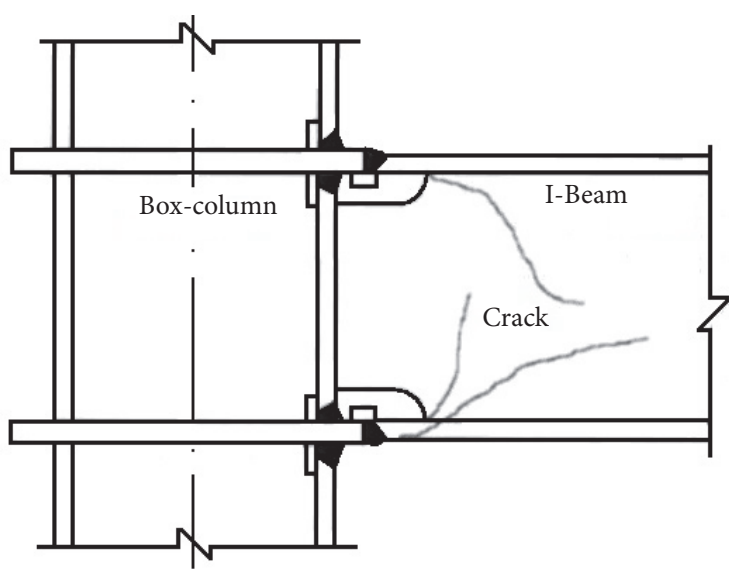

(b) I-beam to box-column

FIgURE 1: Fracture of beam-to-column welded connections.

connections in terms of the relative lateral displacements between the floors of the steel frame. Kato and Akiyama [8] presented a fatigue cumulative damage model as a function of plastic deformations at ends of members. In order to simulate the relationship between the connection moment and relative rotation for the end plate connection, Saranik et al. [9] developed a fatigue damage-based hysteretic model, which is an evolutionary degrading hysteretic model based on the lowcycle fatigue damage index. For prefracture hysteresis, Kuwamura and Takagi [10] proposed and experimentally verified a similitude law, which stated the relationship among ductility amplitude and cumulative ductility as well as number of cycles prior to fracture. Campbell et al. [11] converted the seismic response of the members, such as beam end rotations, to equivalent series of loading cycles by using the rainflow procedure and then evaluated fatigue damage steel frames for predicting their failure or the remaining life based on the similitude law. These approaches are convenient for practical applications in many cases since only the macroseismic response in the structure level, that is, hysteretic loops between bending moment and rotation at the beam ends, is required for the estimation of fatigue resistance performance. However, the shortcoming of these approaches is also obvious. On the one hand, these approaches can hardly predict how cracks initiate and propagate from the local details of welded connections. On the other hand, the realization of these approaches is premised on the $S$ - $N$ curves for the beam-to-column welded connections. Due to size effect, the mechanical properties of scaled welded connections may be different from that of the prototype connections. Therefore, full-size welded connections with various geometries and forms need to be tested to determine the modified MansonCoffin relationship, which is time consuming and expensive.

Although some alternative connections, such as strengthening connection by adding cover plates and reduced beam section connection, are developed to prevent weld from lowcycle fatigue cracking by shifting maximum plastic strain position away from the column flange. However, when the steel frame structure with improved beam-to-column connections is subjected to severe ground motion, it is still necessary to investigate the occurrence probability of plastic hinge at the beams ends and further fatigue failure risk analysis of the connections, which implies that thorough understanding of the local stress and strain fields is required.

A refined numerical analysis is proposed for fatigue crack initiation of beam-to-column welded connections in this paper. A multiscale finite element (FE) model is formulated for the inelastic analysis of steel frames, where the model contains three different length scales elements to describe, respectively, beam-column components, selected critical beam-to-column welded connections based on earthquake resistant conceptual design of steel frame structure and seismic fortification standard of "no damage under weak earthquake" and "no collapse under strong earthquake," and welded seams at the connections. It is explored that the stain status of the fatigue critical points at weld seams of the crucial connections is three-dimensional and their loading pattern is multiaxial nonproportional under strong earthquake excitation. Then taking the experimental relationship between the strain amplitude and the cyclic numbers prior to crack initiation of welded structural steel specimen into consideration, a refined analysis approach is proposed to evaluate fatigue crack initiation life of the welded connections based on the equivalent plastic strain of fatigue critical points.

\section{Multiscale FE Modeling of Steel Frame Structure with Beam-to-Column Welded Connections}

2.1. Multiscale FE Model of Steel Frame Structure. The equations of motion for a multistory and high-rise steel frame structure subjected to strong ground motion can be expressed as

$$
[M]\{\ddot{x}\}+[C]\{\dot{x}\}+\{f(t)\}=-[M]\{1\} \ddot{x}_{g}(t),
$$

where $[M],[C]$, and $\{f\}$ are the mass and damping matrices of the steel frame and the restoring force vector, respectively; $\{\ddot{x}\},\{\dot{x}\}$, and $\{x\}$ are acceleration, velocity, and displacement 


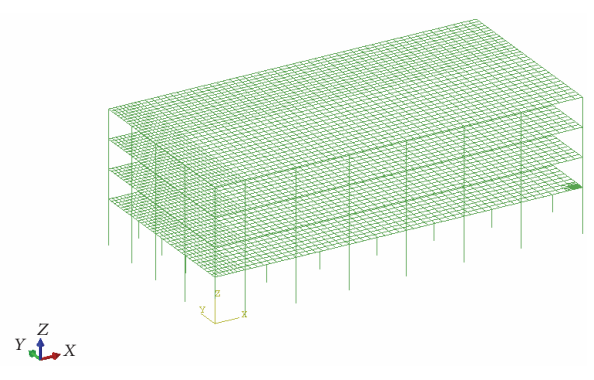

FIGURE 2: Numerical example of a 4-story steel frame.

vectors relative to the ground, respectively; $\{1\}$ is the vector with all elements equal to unit; and $\ddot{x}_{g}(t)$ is the ground acceleration.

It is known that under strong earthquake excitation, column-to-beam welded connections and the partial regions of beams and columns near the critical connections of a steel frame may be in an elastic-plastic stress state, while the remaining parts of the beams and columns are still in the linear elastic range. Although the elastoplastic analysis of the steel frame using full-scale three-dimensional FE model is accurate, it is inefficient and time consuming when the steel frame structure is large. Therefore, the multiscale FE modeling is a proper choice for the refined local elastic-plastic seismic analysis of the welded connections.

The connections are classified as critical ones and normal ones. The particular attention will be paid to the accurate elastic-plastic stress and strain fields at the critical connections and at the beams and columns which are connected with these connections. The multiscale FE model consists of elastic-plastic three-dimensional beam and solid elements. The solid elements with millimeter scale are used for the welded seam zone of the critical connections; the solid elements with centimeter scale are used for the panel zone of critical welded connections and the regions of the beams and columns adjacent to the connections, while the beam elements with meter scale are used for the simulation of the other regions of the beams and columns far away from the key connections and other beams and columns. The multiscale elements of the FE model can be assembled together by assigning the coupling interactions between the elements boundary.

As an example, a four-storey steel frame shown in Figure 2 is used to demonstrate the formulation and analyses. The total height of the steel frame is 19.1 meters; the construction sites are assumed to be category II-III specified in the China Seismic Design Code [12]. The El-Centro earthquake record is selected and its acceleration amplitude is modulated to $6.2 \mathrm{~m} / \mathrm{s}^{2}$ considering the strong earthquake with intensity 9 defined by the Code [12]. The connections are assumed to box columns to I-beams. For the demonstration purpose, only one critical welded connection is selected. The configurations and dimensions of the I-beam and box-column sections are listed in Table 1.

The welding method for the connection is manual arc welding with filler metal of E4301. All welds are single $\mathrm{V}$ groove weld. The construction materials for beams and
TABLE 1: Configurations and dimensions of the beam and column sections.

\begin{tabular}{lcc}
\hline Component & Location & Dimensions \\
\hline \multirow{4}{*}{ Beam } & Outer beams in $x$ direction & $\mathrm{H} 450 \times 250 \times 12 \times 20$ \\
& Inner beams in $x$ direction & $\mathrm{H} 450 \times 200 \times 12 \times 20$ \\
& Outer beams in $y$ direction & $\mathrm{H} 450 \times 250 \times 12 \times 20$ \\
& Inner beams in $y$ direction & $\mathrm{H} 500 \times 300 \times 14 \times 25$ \\
\hline Column & Square columns & $\square 400 \times 400 \times 20 \times 20$ \\
\hline
\end{tabular}

columns are assumed to be Q235B. The details of welded connections are shown in Figure 3.

The commercial FE package ABAQUS [13] is used to formulate the multiscale FE model of the steel frame. The solid elastoplastic element of C3D8R having centimeter scale is used to model the critical welded connection. The beam element of B31 with meter scale considering shear deformation is used to model the beams and columns. For the beams and columns which are linked to the crucial connection, the regions close to the panel zone are modeled by C3D8R and the remaining parts are modeled by B31.

The floor slabs, which play an important role in a steel frame to resist external loads effectively, are modeled by means of shell element S31 in the multiscale FE formulation. The seismic action is transferred by adding the rigid link interaction at common boundaries between the shell elements of slab and the solid element (or the beam element). The typical local multiscale FE model of the frame is shown in Figure 4.

\subsection{Welding Residual Stress Relief of Beam End Seam at Beam-} to-Column Connections. To conduct the refined analysis, it is important to clarify whether the welding residual stresses play important roles in plastic strain at welded connections of steel frames under the strong ground motion excitation. Song [14] has shown that the level of welding stress relief depends on the amplitude of the overload stress. He theoretically justified that if the overload stress exceeds the yield strength of the metal, the welding stresses can be fully relieved. Farajian et al. [15] found that welding residual stress relief occurs when the superposition of welding residual stresses and working stresses exceeds the yield strength of the metal.

The weldment specimens, whose base metal is structural steel of grade Q345 with yield strength of $425 \mathrm{MPa}$, with longitudinal seam at the mid-span, are cyclic loaded with constant amplitude by fatigue test machine and the residual stress distribution along transversal cross section of the specimens is measured as shown in Figure 5. It should be noted that the residual stress distribution is plotted according to stress state at 5 points on the right hand side of centroidal axis of cross section of the specimens, and the stress distribution on the left hand side is given based on the symmetry. It can be seen that when the working stress induced by the imposed cycle load is less than the yield strength of the base material, welding residual stress is partially relieved, while when the working stress is beyond the yield strength, the residual stress can be completely relieved and the residual stress fluctuates 

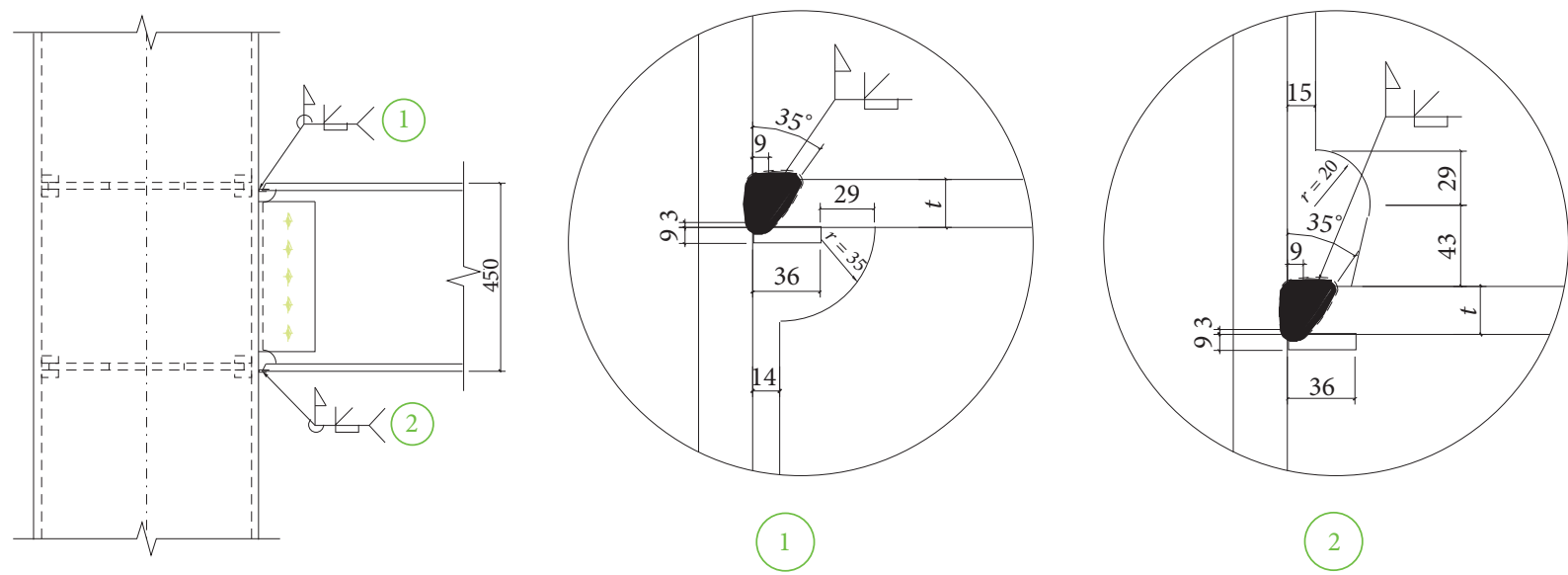

FIGURE 3: Details of welded connections.

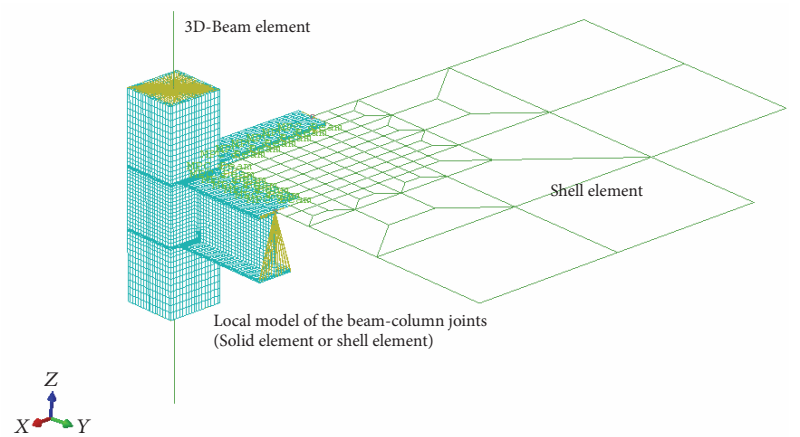

FIGURE 4: Multiscale FE model of the beam-to-column welded connection.

around zero. It is also found that the relief occurs at the end of first cyclic loading and keeps almost stable at the succeeding cyclic loading [16].

When a steel frame structure is subjected to the strong earthquake motion, the welded connections may behave plastically and the stresses at the weld zone may exceed the yield strength of the base metal. Therefore, the welding residual stresses can be fully relieved according to the residual stress relief law, and then welding residual stresses are not taken into consideration in the refined seismic plastic response analysis in the present study.

\subsection{Demarcation between the Elastic Beam Zone and the} Plastic Welded Connection Zone. When the frame is subjected to a strong earthquake excitation, the stresses of partial regions of beams and columns linked to the connection may enter elastoplastic range while the balance may keep in the elastic state. To ensure that the refined solid elements C3D8R can reflect the elastoplastic behavior of the connection and the beams elements B31 can model the elastic behavior of the beams and columns adequately, the coupling boundaries between beam elements and solid ones should be properly determined.

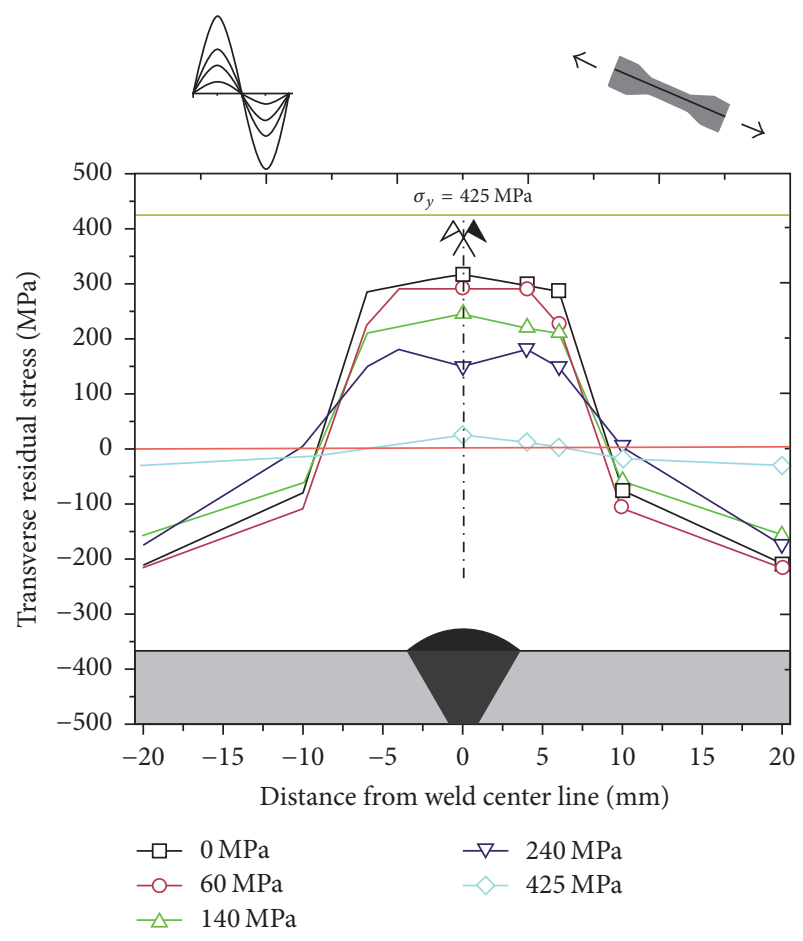

FIgURE 5: Transversal residual stress distribution of the weldment specimen subjected to cyclic loading.

If an elastic beam component is subjected to bending moment, its deformation obeys the Euler- Bernoulli hypotheses. Accordingly, the interfaces between the beam element and solid elements can be divided into two parts. Firstly, the refined modeling region is formulated to contain the beam and column components with sufficient lengths to ensure the elastic response of the coupling constraint sections; for example, the positions at the quarter length of the beam and column near the connection can be taken as the coupling sections. The kinematic coupling technique is employed for establishing coupling interactions between the solid elements 


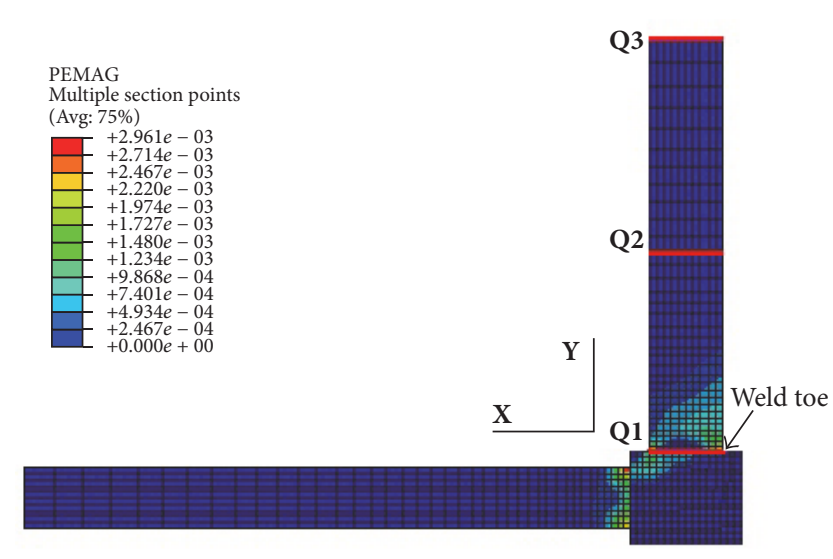

FIGURE 6: PEMAG of the bottom flange.

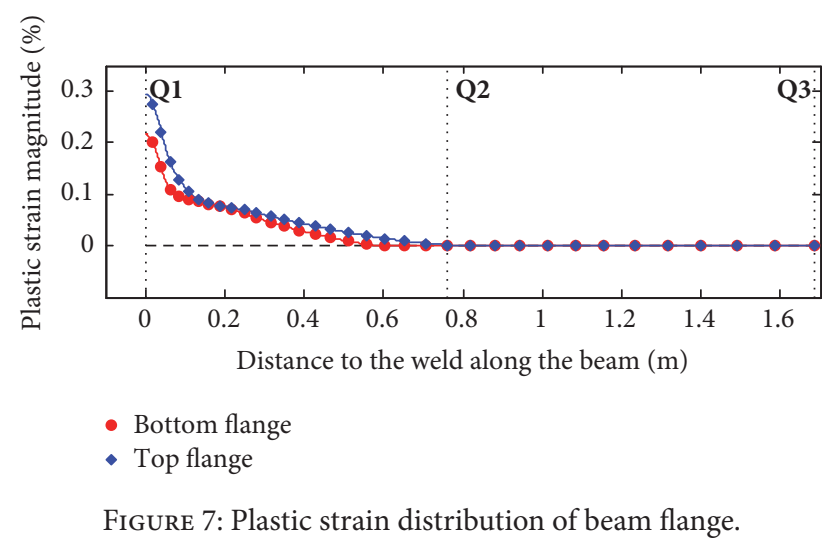

C3D8R for connection regions and the beam elements B31. Secondly, sections of demarcation between the elastic region and the plastic region in the refined welded connection modeling at the maximum response time are used as the coupling sections to rebuild a multiscale FE model.

For the four-storey steel frame shown in Figure 2, the multiscale FE model including a quarter of beam and column components in the refined modeling region is adopted for the first step analysis. Figure 6 displays the plastic strain magnitude (PEMAG) of the corner welded connection at the first floor at the time $t=11.6 \mathrm{~s}$.

It can be seen in Figure 6 that the stress on a part of the section Q1 in the $Y$ direction is plastic, while the deformation of the sections Q2 and Q3 is elastic. The maximum plastic deformation of the welded connection occurs at the welded toe. The plastic strain distribution of the beam flange from the welded toe to the coupling section along $y$ direction is shown in Figure 7. It can be seen that the section Q2 can be approximately regarded as the demarcation section between the elastic and elastic-plastic regions, which can be used as the coupling position between the solid and beam elements in the subsequent numerical analysis. Hence, the region of the beam from the section Q1 to the section Q2 is modeled by solid elements and the remaining region of the beam is meshed by beam elements.
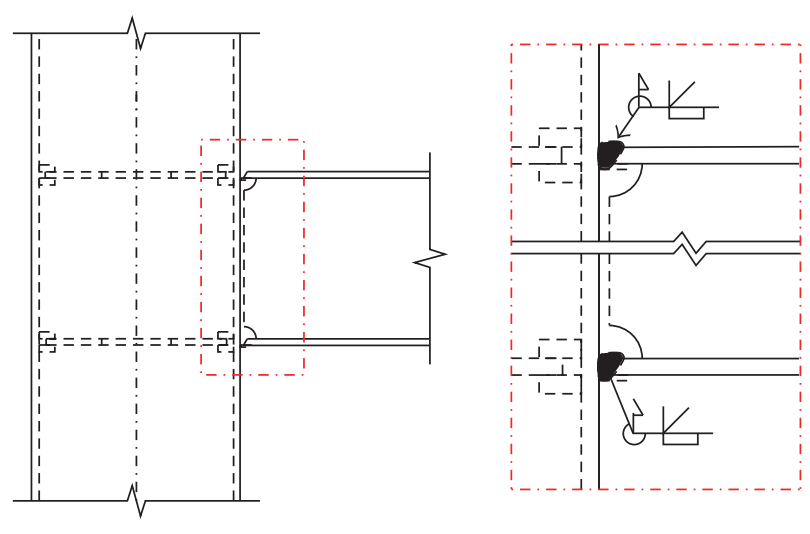

FIGURE 8: Weld of the beam-to-column connection.

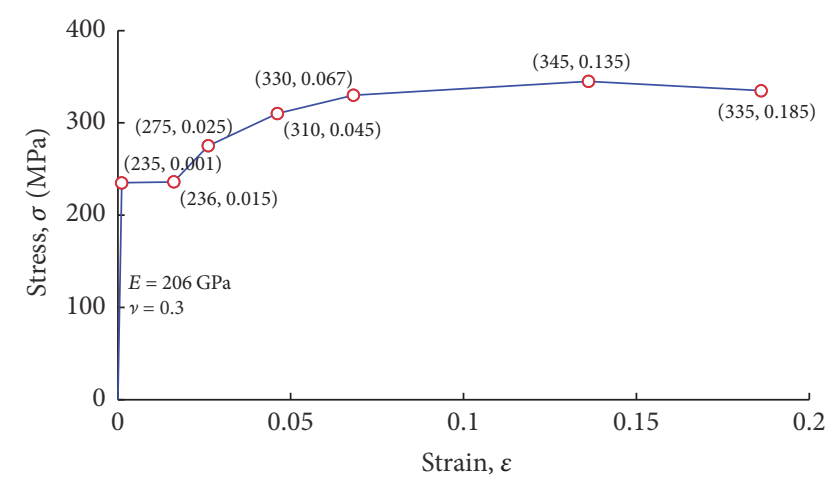

- ABAQUS material data

FIgURE 9: Constitutive model of Q235B steel.

\section{Three-Dimensional Plastic Analyses of Critical Positions at Welded Connection for Fatigue}

3.1. Seismic Plastic Response of Fatigue Critical Positions. A typical welded connection of the I-beam and box-column is shown in Figure 8. The welded seam of the connection is located at the end of the beam.

It is assumed that large deformations of the welded seam occur along the longitudinal direction of the beam. In this case, the transverse deformations of the welded seam due to Poisson's ratio should be restricted by the column flange, and then the local stress and strain states of the welded zones are three-dimensional, which cannot be treated by the onedimensional classical beam theory. Therefore the multiscale FE model is adopted for the three-dimensional inelastic analysis.

In the analysis, based on the experimental results the elastoplastic constitutive model is used to simulate the mechanical properties of the Q235B steel as shown in Figure 9.

When the steel frame is subjected to the earthquake of intensity 9, Figure 10 shows the magnitudes of the plastic strains of the bottom flange of the beam linked with the critical welded connection at the first floor in the $Y$ direction. 


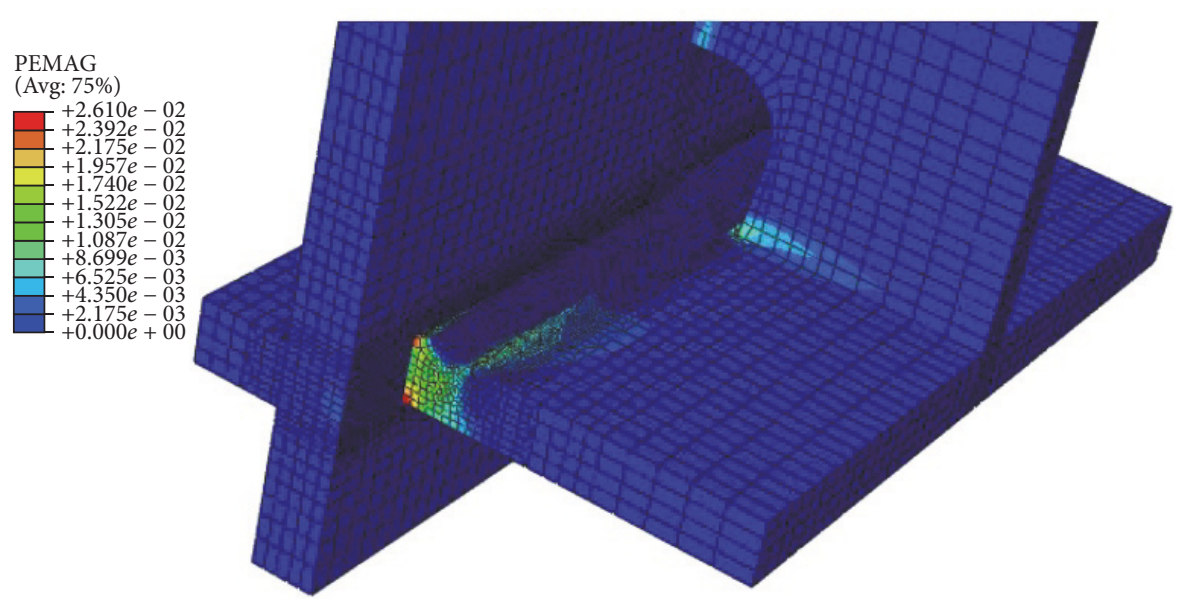

Figure 10: Plastic strain magnitude of the bottom flange weld at $t=2.36 \mathrm{~s}$.
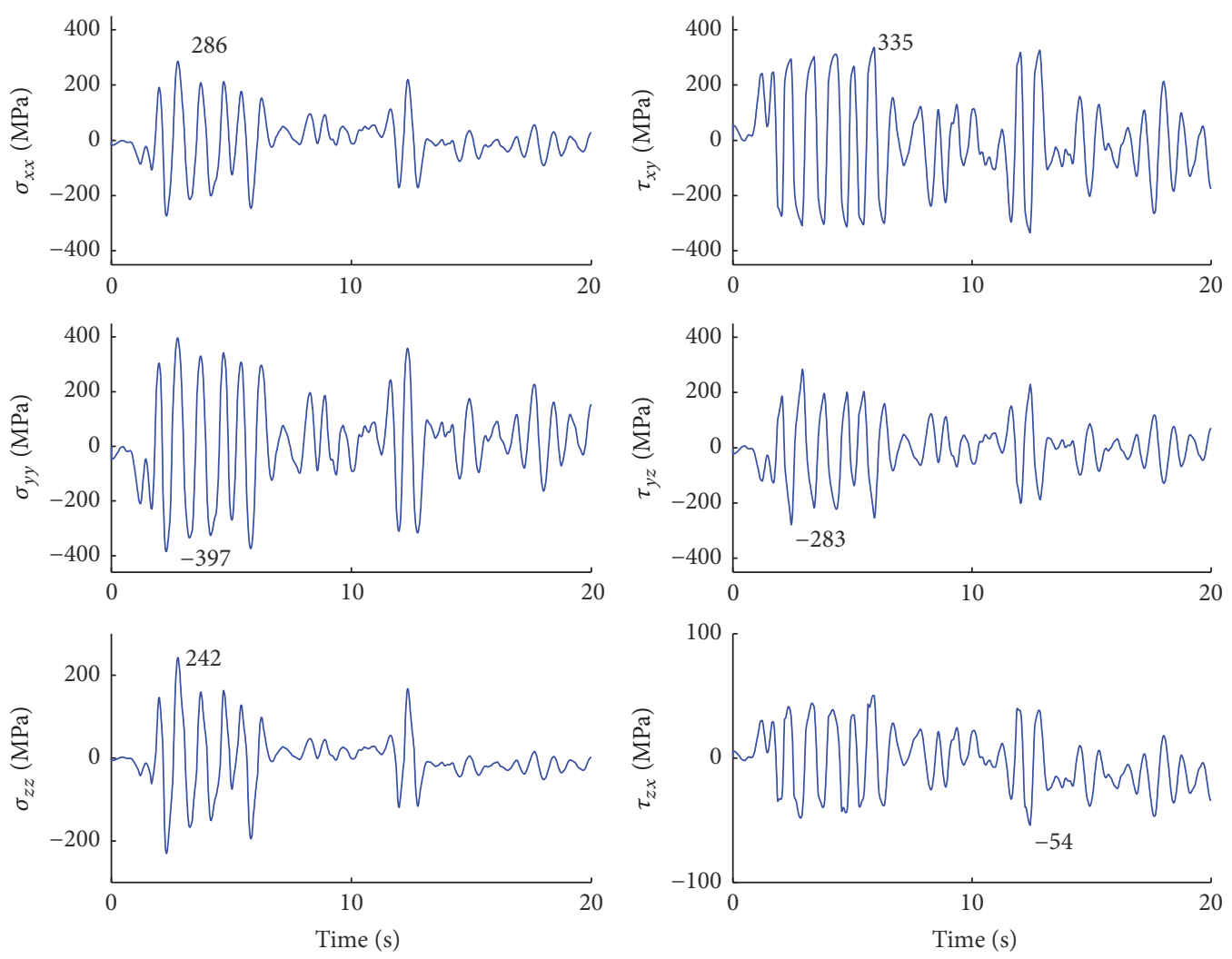

FIGURE 11: Stress time history of the weld toe.

The maximum plastic strain $2.61 \times 10^{-2}$ occurs at the weld toe of the bottom flange at the time $t=2.36 \mathrm{~s}$. Accordingly, the weld toe can be regarded as the fatigue critical position of the welded connection.

The six stress time histories of the weld toe, that is, the fatigue critical position, are shown in Figure 11. Obviously, the stress state of the weld toe is three-dimensional. It can also be found that the maximum values of three normal stresses are larger than yield strength of Q235B steel.
The normal stress distribution at the time $t=2.36 \mathrm{~s}$ along the beam axial direction starting from the column flange is shown in Figure 12. It can be seen that the three-dimensional stress state exists only in a very narrow band near the column flange. It is noted that the normal stresses $\sigma_{x x}$ and $\sigma_{z z}$ in $x$ and $z$ directions decrease rapidly from the maximum value to zero within a distance of about $0.4 \mathrm{~m}$, respectively, and the normal stress $\sigma_{y y}$ in the $y$ direction reduces to $177.6 \mathrm{MPa}$ at the section with the distance of $0.6 \mathrm{~m}$ away from the weld 


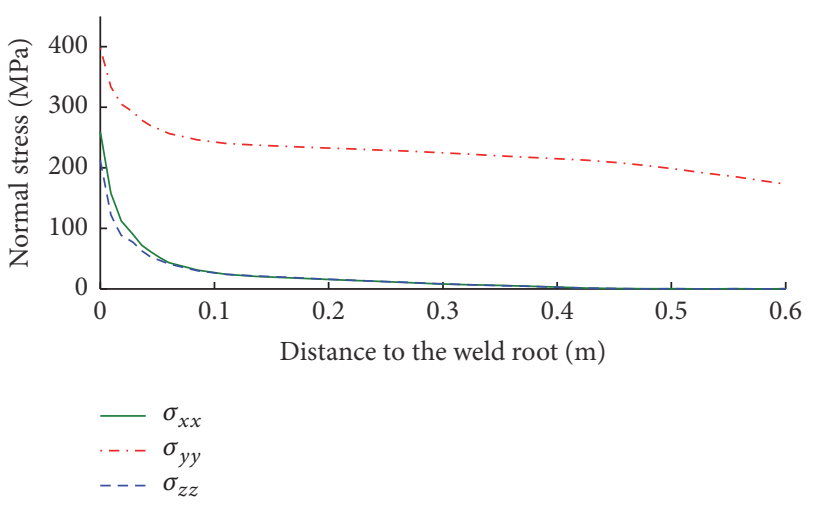

FIGURE 12: Normal stress distribution along the beam axial direction.

toe, which is compatible with the theoretical solution at the corresponding section based on the classical beam theory. Therefore, it can be concluded that the three-dimensional stress state is simply limited in the local area of the weld toe. That is because the column restraining effects on the beam decrease with an increase of the distance away from the weld toe.

\subsection{Nonproportional Loading Condition of Fatigue Critical} Position. In order to select a proper approach for fatigue crack initiation analyses of beam-to-column welded connection, the primary task is to evaluate the three-dimensional strain state at the critical point, which may be produced either by proportional loading or by nonproportional loading. Based on multiaxial fatigue theory and experimental study [17-20], if the three-dimensional seismic strain state is produced by proportional loading, the equivalent strain method can give satisfactory prediction of the fatigue life, while the critical plane approach is suitable for the analysis when the strain state is produced by the nonproportional loading.

Since the mechanism of the fatigue crack initiation for the structural steel satisfies the metal crystal slip theory, fatigue crack initiation occurs on the plane with the maximum shear strain, which can be defined as the critical plane according to the multiaxial fatigue theory $[21,22]$. If the strain state is proportional, the angle of the critical plane is constant, while if the strain state is nonproportional, the angle time history of the critical plane varies. Therefore, the strain states of the weld zone can be evaluated through the time-varying plane angles of maximum shear strains.

The strain tensor at a material point can be written as

$$
\boldsymbol{\varepsilon}=\left[\begin{array}{lll}
\varepsilon_{x x} & \varepsilon_{x y} & \varepsilon_{x z} \\
\varepsilon_{y x} & \varepsilon_{y y} & \varepsilon_{y z} \\
\varepsilon_{z x} & \varepsilon_{z y} & \varepsilon_{z z}
\end{array}\right] .
$$

A point on the inclined plane can be selected as the origin of an $X^{\prime} Y^{\prime} Z^{\prime}$ axis system with the $X^{\prime}$ axis is normal to the plane and $Y^{\prime}$ and $Z^{\prime}$ are on the plane as shown in Figure 13. The transformation equation for three strain components on

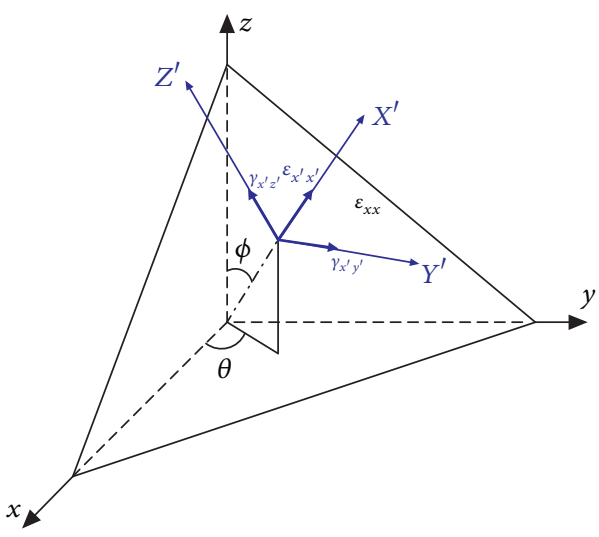

FIGURE 13: Strain acting on a plane in a three-dimensional coordinate system.

the inclined plane in terms of two angles $\theta$ and $\phi$ can be expressed as [17]

$$
\begin{aligned}
\varepsilon_{x^{\prime} x^{\prime}}= & \varepsilon_{x x} a_{11}^{2}+\varepsilon_{y y} a_{12}^{2}+\varepsilon_{z z} a_{13}^{2} \\
& +\left(\gamma_{x y} a_{11} a_{12}+\gamma_{x z} a_{11} a_{13}+\gamma_{y z} a_{13} a_{12}\right) \\
\gamma_{x^{\prime} y^{\prime}}= & \varepsilon_{x x} a_{11} a_{21}+\varepsilon_{y y} a_{12} a_{22}+\varepsilon_{z z} a_{13} a_{33} \\
& +\frac{1}{2} \gamma_{x y}\left(a_{11} a_{22}+a_{12} a_{21}\right) \\
& +\frac{1}{2} \gamma_{y z}\left(a_{12} a_{23}+a_{13} a_{22}\right) \\
& +\frac{1}{2} \gamma_{z x}\left(a_{13} a_{21}+a_{11} a_{23}\right) \\
\gamma_{x^{\prime} z^{\prime}=} & \varepsilon_{x x} a_{11} a_{31}+\varepsilon_{y y} a_{12} a_{32}+\varepsilon_{z z} a_{13} a_{33} \\
& +\frac{1}{2} \gamma_{x y}\left(a_{11} a_{32}+a_{12} a_{31}\right) \\
& +\frac{1}{2} \gamma_{y z}\left(a_{12} a_{33}+a_{13} a_{32}\right) \\
& +\frac{1}{2} \gamma_{z x}\left(a_{13} a_{31}+a_{11} a_{33}\right)
\end{aligned}
$$

where

$$
\begin{aligned}
& {\left[\begin{array}{lll}
a_{11} & a_{12} & a_{13} \\
a_{21} & a_{22} & a_{23} \\
a_{31} & a_{32} & a_{33}
\end{array}\right]} \\
& \quad=\left[\begin{array}{ccc}
\cos \theta \sin \phi & \sin \theta \sin \phi & \cos \phi \\
-\sin \theta & \cos \theta & 0 \\
-\cos \theta \cos \phi & -\sin \theta \cos \phi & \sin \phi
\end{array}\right] .
\end{aligned}
$$

Therefore the critical plane of maximum shear strain at a point of the weld zone can be located by a pair of angles $\theta$ and $\phi$ as shown in Figure 13. For the proportional loading condition, the plane of maximum shear strain remains 


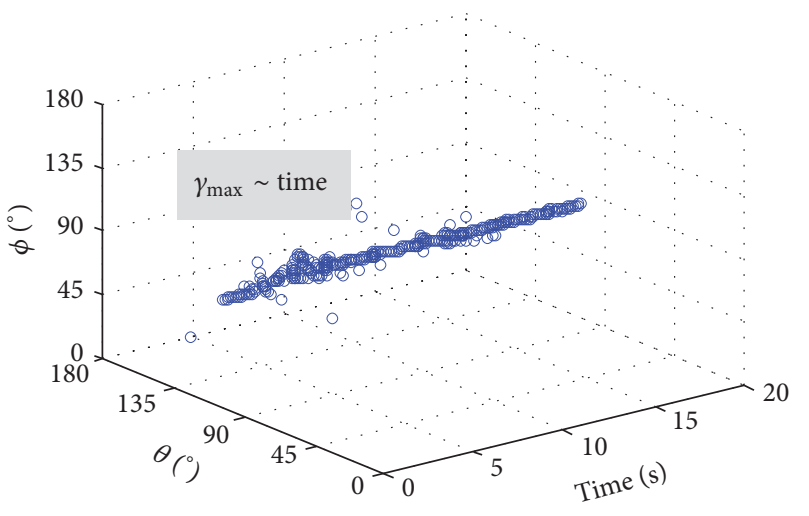

(a) Intensity of 6

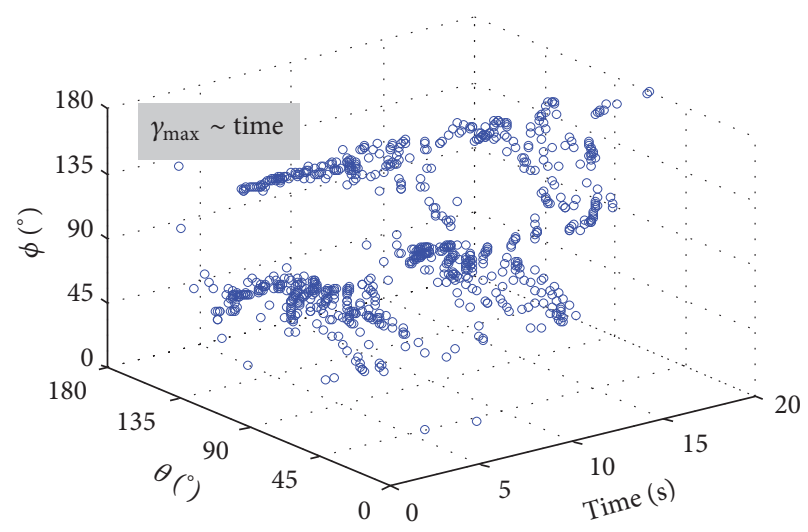

(b) Intensity of 9

FIGURE 14: Time-varying angle of maximum shear strain at the fatigue critical point in the case of rare earthquake.

unchanged during the earthquake, which means the angles $\theta$ and $\phi$ are constant, while, for the nonproportional condition, the critical plane varies, and so the angles $\theta$ and $\phi$ also vary.

The FE results for the time histories of angles $\theta$ and $\phi$ for the maximum shear strain at the fatigue critical point under earthquake excitation are shown in Figure 14(a) for seismic fortification intensity of 6 and in Figure 14(b) for seismic fortification intensity of 9. It can be seen from Figure 14(a) that the plane angles are almost in a straight line, which implies that the plane with the maximum shear strain is almost unchanged and so the loading status is proportional. However, Figure 14(b) shows that the points scatter for intensity of 9 , which means that the strain state at the critical point is caused by nonproportional loading. Therefore, the strain state of the same critical point is much related to the earthquake intensity. The main reason is that the strain of the fatigue critical position of the welded connection is in the elastic range under the earthquake of intensity 6 ; the strain components increase or decrease proportionally with the earthquake loading. Subsequently, the plane of the maximum shear strain remains unchanged and the strain state is proportional. However, under the earthquake of intensity 9 , the stress of the fatigue critical point becomes elastoplastic, and consequently the strain rates in three directions of the critical point are not synchronized. Therefore, the plane of the maximum shear strain changes with the earthquake loads and the strain state of the fatigue critical point is nonproportional. Therefore, the fatigue crack initiation life of the welded connection under a strong earthquake excitation should be predicted by the critical plane method.

\section{Fatigue Life Prediction of Q235B Steel Weldment}

4.1. Specimens and Loading Path. To realize the refined analysis for fatigue crack initiation life of the welded connections of the steel frame under a strong earthquake excitation, experiments for determining fatigue lives under uniaxial and multiaxial loading conditions are conducted on the Q235B steel weldment.
The weldment has a tubular geometry with the outside and inside diameters of $18 \mathrm{~mm}$ and $14 \mathrm{~mm}$, respectively. The wall thickness in the gage section is $2 \mathrm{~mm}$. The total length of the weldment is $185 \mathrm{~mm}$, and an $18 \mathrm{~mm}$ long welded zone is at the center of the gage length. The geometry of the weldment is displayed in Figure 15. The welded specimen is made by the manual $\mathrm{CO}_{2}$ gas-shielded welding process. The welding wire of MG70S- 6 with a diameter of $2 \mathrm{~mm}$ is used. The manufacture of the welded metal specimen is followed by $[23,24]$. A well-designed notch is first machined at the center of the base metal bar, and the notch is then filled with weld metal. Finally, the welded metal specimen is machined to the designed shape.

Multiaxial fatigue tests are carried out on a MTS809 tension-torsion servohydraulic testing system under straincontrolled loading using a tension-torsion strain extensometer, which is mounted at the center of the outside of the specimen gage section to measure the strain responses. The uniaxial, in-phase, and $90^{\circ}$ out-of-phase loading are sinusoidal wave with constant amplitudes and the three test strain paths are displayed in Figure 16. The horizontal axis is the term of axial strain $\varepsilon$, and the vertical axis is the term of shear strain $\gamma / \sqrt{3}$.

4.2. Multiaxial Cyclic Mechanical Properties. The cyclic mechanical properties of metal materials can be expressed by Ramberg-Osgood model as follows [25]:

$$
\frac{\Delta \varepsilon_{\mathrm{eq}}}{2}=\frac{\Delta \varepsilon_{e}}{2}+\frac{\Delta \varepsilon_{p}}{2}=\frac{\Delta \sigma_{\mathrm{eq}}}{2 E}+\left(\frac{\Delta \sigma_{\mathrm{eq}}}{2 K^{\prime}}\right)^{1 / n^{\prime}},
$$

where $K^{\prime}$ is the cyclic hardening coefficient, $n^{\prime}$ is the cyclic hardening exponent, and $\Delta \varepsilon_{e} / 2$ and $\Delta \varepsilon_{p} / 2$ are elastic strain amplitude and the plastic strain amplitude, respectively. Then, the fitting cyclic stress-strain curves of Q235B weldment under different loading paths are shown in Figure 17.

It can be seen from Figure 17 that fitting cyclic stressstrain curve for the weldment under in-phase loading is similar to those obtained for uniaxial loading, while the fitting cyclic stress-strain curve for the $90^{\circ}$ out-of-phase 


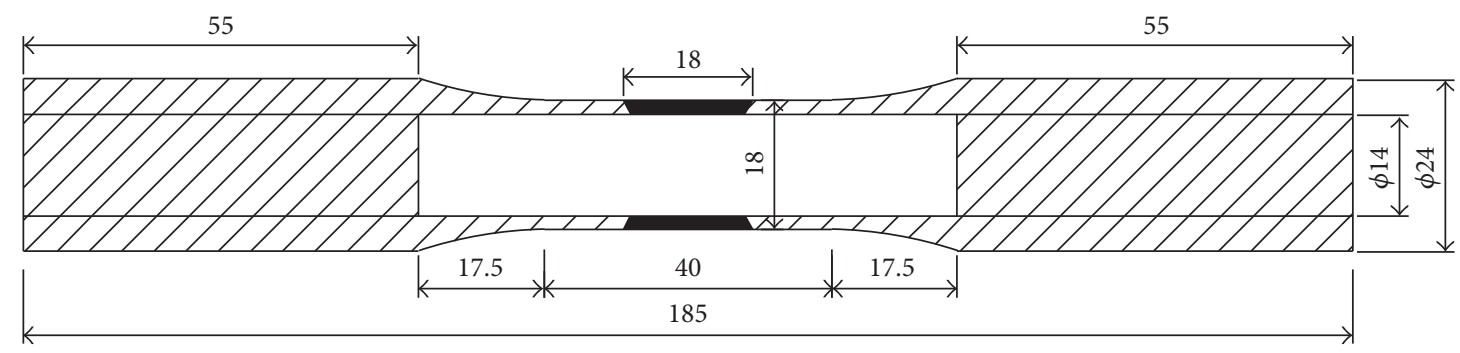

Figure 15: Geometry of the welded metal specimen (unit: $\mathrm{mm}$ ).

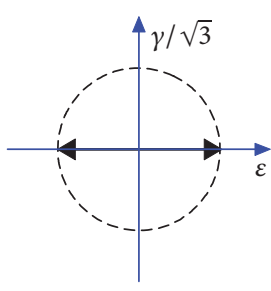

(a)

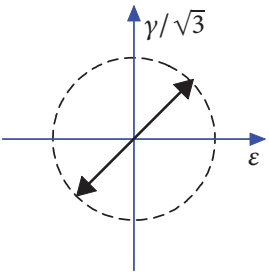

(b)

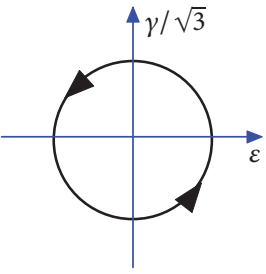

(c)

FIGURE 16: Fatigue test loading paths: (a) uniaxial (UA), (b) in-phase (IP), and (c) $90^{\circ}$ out-of-phase (OP).

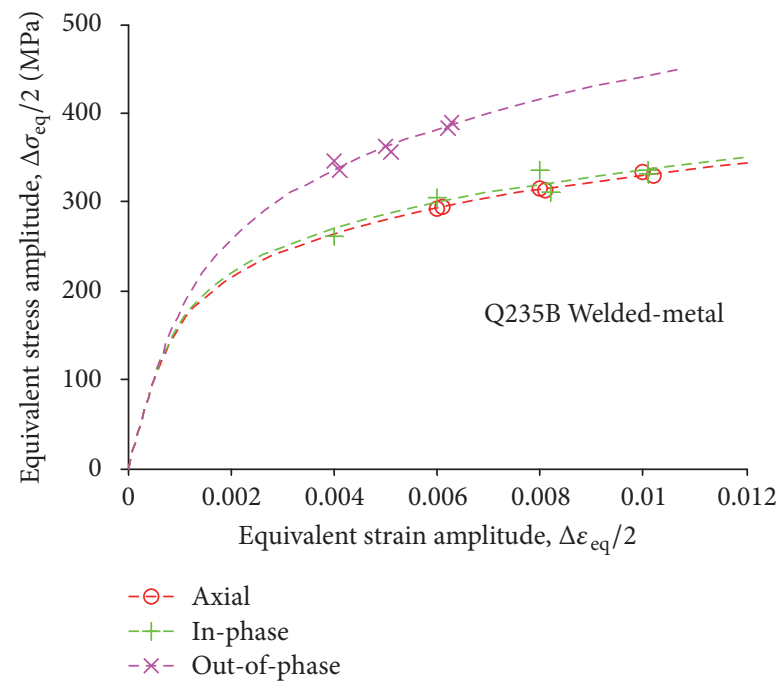

FIGURE 17: The cyclic stress-strain curves of Q235B weldment under different loading paths.

loading conditions is above those related to the uniaxial loading case, which indicates that a significant additional cyclic hardening effect occurs for the weldment under the out-of-phase loading conditions.

\subsection{Multiaxial Low-Cycle Fatigue Performance Parameters.} In the uniaxial fatigue analysis, the Manson-Coffin equation in terms of the equivalent strain parameter is widely applied for fatigue life estimation.

$$
\frac{\Delta \varepsilon_{\mathrm{eq}}}{2}=\frac{\Delta \varepsilon_{e}}{2}+\frac{\Delta \varepsilon_{p}}{2}=\frac{\sigma_{f}^{\prime}}{E}\left(2 N_{f}\right)^{b}+\varepsilon_{f}^{\prime}\left(2 N_{f}\right)^{c}
$$

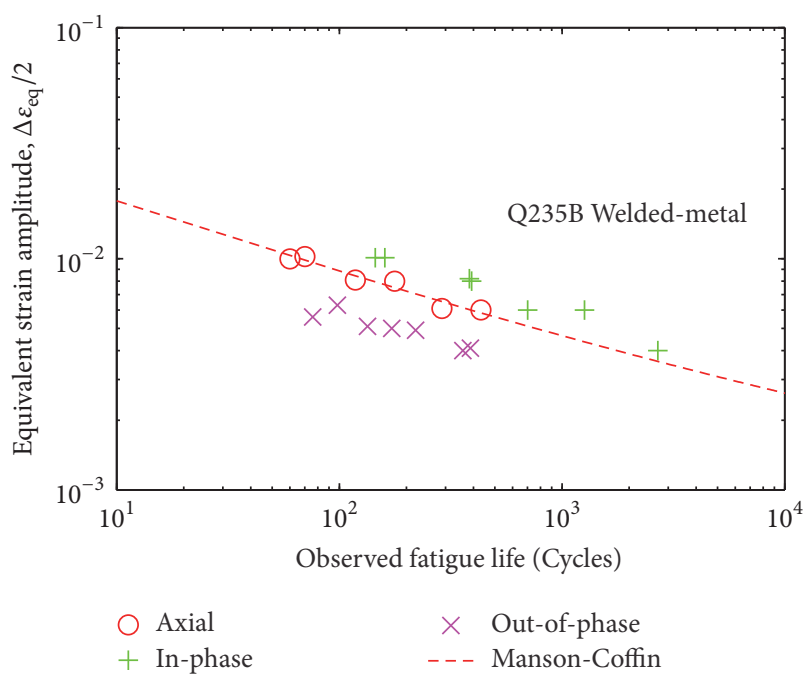

FIGURE 18: Correlation of the equivalent strain parameters versus fatigue life.

where $N_{f}$ is fatigue crack initiation life, which is obtained by fatigue tests. Since it hardly captures the instant when the cracks occur, usually $N_{f}$ is assumed as the number of cycles at which a $30 \%$ drop from the maximum values occurred in either tensile or shear stress [23]. $\sigma_{f}^{\prime}, \varepsilon_{f}^{\prime}, b$, and $c$ are the fatigue strength coefficient, the fatigue ductility coefficient, the fatigue strength exponent, and the fatigue ductility exponent, respectively. The fatigue performance parameters in (6) are listed in Table 2 for the weldment under different loading paths.

Figure 18 shows the relationships of equivalent strain parameters versus fatigue life under the investigated loading conditions for the welded metal specimens. The dashed line 


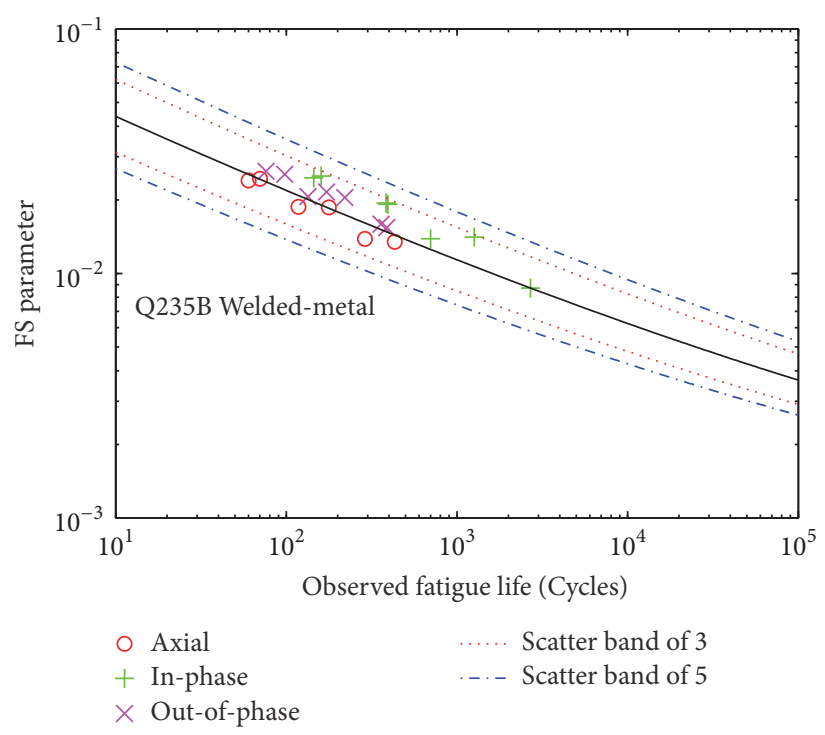

(a)

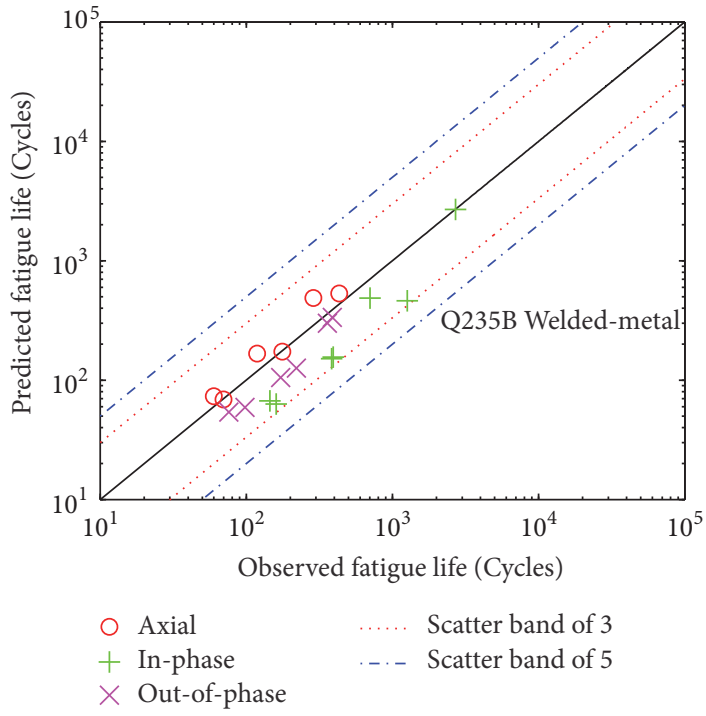

(b)

FIGURE 19: Correlation of the FS parameters versus fatigue life.

TABLE 2: Fatigue properties of Q235B welded specimens.

\begin{tabular}{lccc}
\hline Fatigue properties & Uniaxial tests & In-phase tests & $90^{\circ}$ out-of-phase tests \\
\hline$\sigma_{f}^{\prime}(\mathrm{MPa})$ & 481.14 & 508.27 & 519.35 \\
$\varepsilon_{f}^{\prime}$ & 0.0375 & 0.0654 & 0.0202 \\
$b$ & -0.0755 & -0.0708 & -0.3555 \\
$c$ & -0.3154 & -0.0624 & -0.3181 \\
\hline
\end{tabular}

in Figure 18 is the fitting Manson-Coffin curve based on the equivalent strain amplitude. It can be seen that the Mansoncoffin equation can conservatively assess fatigue life under in-phase proportional loading path, while it is overestimated for $90^{\circ}$ out-of-phase loading conditions. Therefore, MansonCoffin is not a suitable estimation for nonproportional loading path.

4.4. FS Model of Multiaxial Fatigue Life Prediction. Fatemi and Socie [18] proposed a widely accepted critical plane concept using the maximum normal stress, which can reflect the effect of nonproportional cyclic additional hardening on multiaxial fatigue damage. The Fatemi-Socie (FS) model can give proper estimation for most metal materials.

$$
\begin{aligned}
& \frac{\Delta \gamma_{\max }}{2}\left(1+k \frac{\sigma_{n, \max }}{\sigma_{y}}\right) \\
& =\left[\left(1+v_{e}\right) \frac{\sigma_{f}^{\prime}}{E}\left(2 N_{f}\right)^{b}+\left(1+\nu_{p}\right) \varepsilon_{f}^{\prime}\left(2 N_{f}\right)^{c}\right] \\
& \cdot\left(1+k \frac{\sigma_{f}^{\prime}}{2 \sigma_{y}}\left(2 N_{f}\right)^{b}\right),
\end{aligned}
$$

where $\Delta \gamma_{\max } / 2$ is the maximum shear strain amplitude acting on the critical plane, $\sigma_{n, \max }$ is the maximum normal stress acting on the critical plane, $\sigma_{y}$ is the material yield strength, and $k$ is an experimental coefficient. The parameter $k$ in FS model can be found by fitting fatigue data from uniaxial fatigue data. However, according to the study by Shamsaei and Fatemi [26] and Wu et al. [27], the predicted fatigue lives are not highly sensitive to the exact $k$ value in the region of the short lives. Thus they suggested that the $k$ value in the FS parameter model can be approximately assumed as $k=1.0$ $[17,26,27]$. Figure 19 gives the comparison of fatigue life prediction between the FS parameter and the tests.

It can be seen from Figure 19 that FS parameters and experimental fatigue lives are well correlated for the Q235B weldment for all loading conditions and all predicted fatigue lives fall into the error scope of 3 . Therefore, FS parameter is suitable for the multiaxial fatigue damage evaluation of the fatigue critical point of the welded connections.

\section{Fatigue Crack Initiation Life Prediction of Critical Points at Welded Connections}

5.1. Determination of Critical Plane. From Figure 14 it can be found that the maximum shear strain plane of the fatigue 

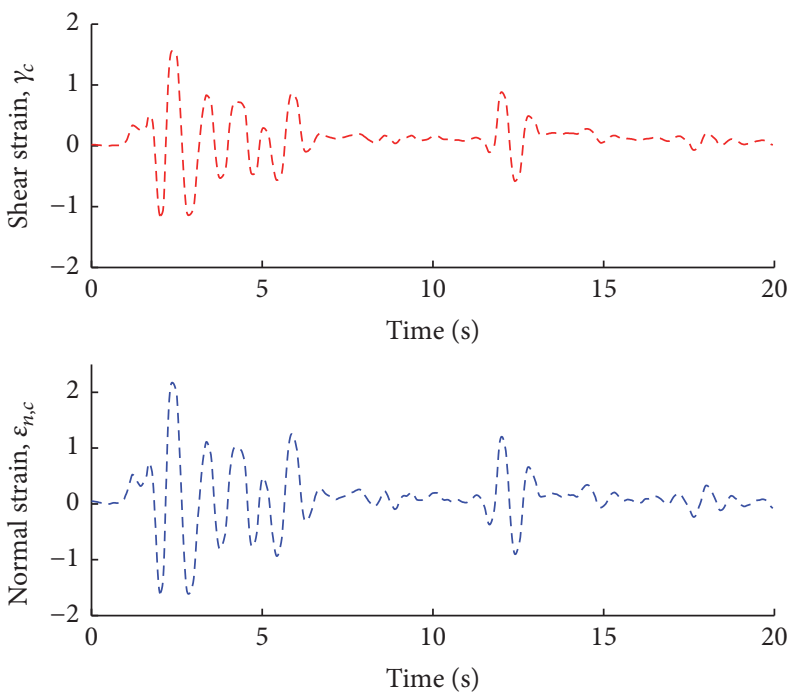

FIGURE 20: The normal strain and shear strain time histories of critical plane.

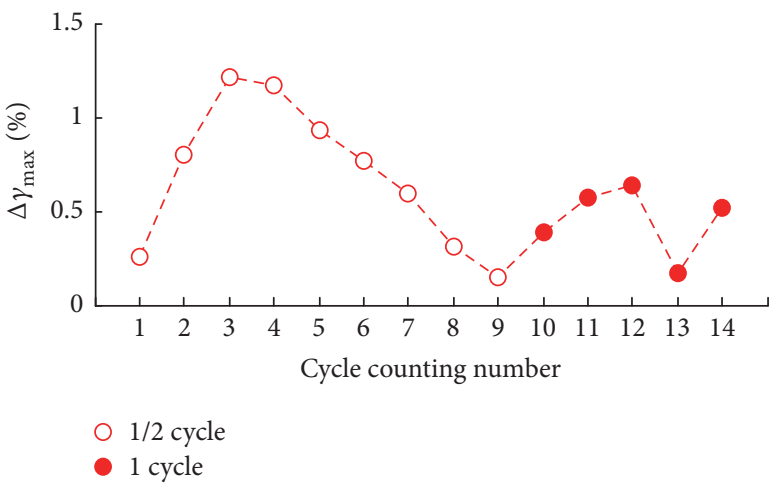

(a) Maximum shear strain range

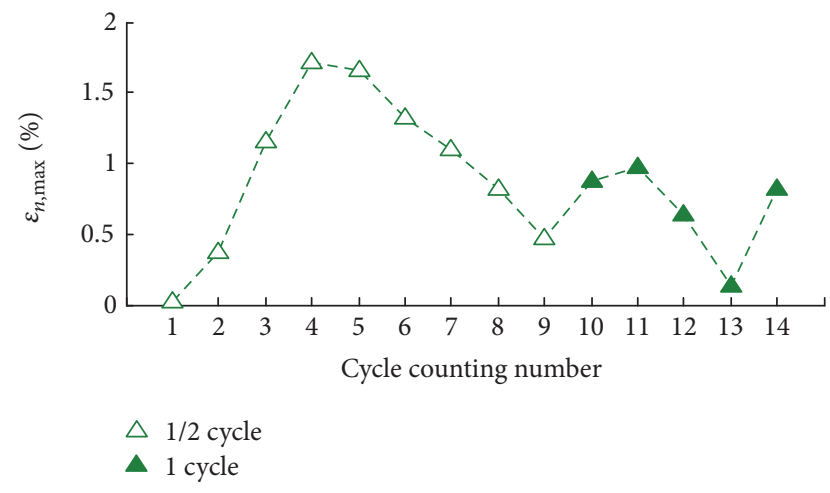

(b) Maximum normal strain

FIGURE 21: Cyclic rainflow counting results of shear strain range and normal strain of critical plane.

critical point varies when the steel frame is subjected to strong earthquake excitation. So the weighted average method is a reasonable choice to determine the position of critical plane.

The weighted mean value of maximum damage critical plane of the fatigue sensitive point is defined as

$$
\begin{aligned}
\bar{\theta} & =\frac{1}{W} \sum_{i=1}^{n} \theta\left(t_{i}\right) w\left(t_{i}\right), \\
w\left(t_{i}\right) & =\frac{\gamma_{t \max }-\gamma_{\min }}{\gamma_{\max }-\gamma_{\min }},
\end{aligned}
$$

where $\theta\left(t_{i}\right)$ is the maximum shear strain plane at every instant of time, $w\left(t_{i}\right)$ is weighted function, $W$ is the sum of $w\left(t_{i}\right), \gamma_{\min }$ and $\gamma_{\max }$ are minimum and maximum shear strain during the whole time, respectively, and $\gamma_{t, \max }$ is the maximum shear strain at every instant of time. In the example, the weighted average angle of the critical plane is $\bar{\theta}\left(52^{\circ}, 89^{\circ}\right)$, and then the normal strain and shear strain time histories of critical plane are calculated, as shown in Figure 20.
5.2. Crack Initiation Life Prediction of Fatigue Critical Point. Based on the cyclic rainflow counting algorithm, the cycle counting number for shear strain range and the normal strain are obtained according to the normal strain and shear strain time histories of critical plane, as shown in Figure 21.

Substituting the cyclic rainflow counting results of shear strain range and normal strain during earthquake excitation time of 20 seconds into FS parameter, fatigue life $N_{f, i}$ under each strain cycle is individually calculated. Then the total fatigue damage can be determined by Miner linear fatigue damage accumulation theory as

$$
D=\sum_{i=1}^{14} \frac{n_{i}}{N_{f, i}}=0.562
$$

\section{Conclusions}

The paper presented a refined analysis of elastoplastic behavior of beam-to-columns welded connection of the steel frame 
under strong earthquake by using the multiscale FE modeling technique. The major findings are listed as follows:

(1) To assess the occurrence and progressive failure process of the beam-to-column welded connections of steel frames under the strong earthquake, the multiscale FE modeling technique is needed to accurately analyze local elastoplastic behavior of the welded connections for subsequent fatigue analyses.

(2) Numerical results show that the stress and strain fields at the beam-to-column welded connections during strong earthquake are three-dimensional. The three normal strains are in the plastic or plastic-hardening phase, so the loading path of the fatigue critical point is multiaxial nonproportional.

(3) Since the seismic strain condition of fatigue critical point of beam-to-column welded connection is nonproportional under strong earthquake with larger fortification intensity, the FS parameter of critical plane method can be adopted to accurately predict fatigue crack initiation life analysis obtained by tension-torsion biaxial test of the structural steel weldment.

\section{Conflicts of Interest}

The authors declare that they have no conflicts of interest.

\section{Acknowledgments}

The authors are grateful for the financial support from the National Natural Science Foundation of China under Grant no. 51438002 and no. 51378409.

\section{References}

[1] E. Watanabe, K. Sugiura, K. Nagata, and Y. Kitane, "Performances and damages to steel structures during the 1995 Hyogoken-Nanbu earthquake," Engineering Structures, vol. 20, no. 4-6, pp. 282-290, 1998.

[2] E. P. Popov, T.-S. Yang, and S.-P. Chang, "Design of steel MRF connections before and after 1994 Northridge earthquake," Engineering Structures, vol. 20, no. 12, pp. 1030-1038, 1998.

[3] G. Q. Li, F. F. Sun, and Z. Y. Shen, "Fracture behavior of welded beam-to-column connections of steel moment frames under severe earthquakes," Journal of Building Structures, vol. 4, pp. 19-28, 1998, (in Chinese).

[4] G. Q. Li and S. W. Chen, "From the damage by Wenchuan earthquake to the application of steel building in seismic zone," Progress in Steel Building Structures, vol. 10, pp. 1-7, 2008, (in Chinese).

[5] M. Nakashima, K. Inoue, and M. Tada, "Classification of damage to steel buildings observed in the 1995 Hyogoken-Nanbu earthquake," Engineering Structures, vol. 20, no. 4-6, pp. 271-281, 1998.

[6] H. Krawinkler and M. Zohrei, "Cumulative damage in steel structures subjected to earthquake ground motions," Computers \& Structures, vol. 16, no. 1-4, pp. 531-541, 1983.

[7] C. Bernuzzi, L. Calado, and C. A. Castiglioni, "Ductility and load carrying capacity prediction of steel beam-to-column connections under cyclic reversal loading," Journal of Earthquake Engineering, vol. 1, no. 2, pp. 401-432, 1997.
[8] B. Kato and H. Akiyama, Transactions of the Architectural Institute of Japan, vol. 237, Proc Architectural Institute of Japan, 1975.

[9] M. Saranik, D. Lenoir, and L. Jezequel, "Effect of low fatigue damage in the end plate connection on steel frame seismic demands," in Proceedings of the 8th Int. Conf. on Structural Dynamics, Leuven, Belgium, 2011.

[10] H. Kuwamura and N. Takagi, "Similitude law of prefracture hysteresis of steel members," Journal of Structural Engineering, vol. 130, no. 5, pp. 752-761, 2004.

[11] S. D. Campbell, R. M. Richard, and J. E. Partridge, "Steel moment frame damage predictions using low-cycle fatigue," in Proceedings of the 14th World Conf on Earthquake Engineering, Beijing, China, 2008.

[12] National Standard of the People's Republic of China, Code for seismic design of buildings (GB50011-2010), Architecture and Building Press, Beijing, China, 2010, (in Chinese).

[13] ABAQUS, Standard user's manual version 6.10-1, Hibbitt Karlsson and Sorensen Inc, 2009.

[14] T. M. Song, Generation and elimination of welding residual stress, Petrochemical Press, Beijing, China, 2005, in Chinese.

[15] M. Farajian, T. Nitschke-Pagel, and K. Dilger, "Relaxation of welding residual stresses - Part I: Under quasi-static loading," International Journal of Microstructure and Materials Properties, vol. 7, no. 1, pp. 3-15, 2012.

[16] W. L. Qu, M. Wang, and E. N. Zhao, "Effect of plastic cycle strain on the welding residual stress and its relaxation," Research Report of Wuhan University of Technology, vol. No. 1603, 2016.

[17] D. F. Socie and G. B. Marquis, Multiaxial Fatigue, SAE International, Warrendale, Pa, USA, 2000.

[18] A. Fatemi and D. F. Socie, "A critical plane approach to multiaxial fatigue damage including out-of-phase loading," Fatigue \& Fracture of Engineering Materials \& Structures, vol. 11, no. 3, pp. $149-165,1988$.

[19] S. De-Guang and W. De-Jun, "A new multiaxial fatigue damage model based on the critical plane approach," International Journal of Fatigue, vol. 20, no. 3, pp. 241-245, 1998.

[20] J. Li, Z.-P. Zhang, Q. Sun, and C.-W. Li, "Multiaxial fatigue life prediction for various metallic materials based on the critical plane approach," International Journal of Fatigue, vol. 33, no. 2, pp. 90-101, 2011.

[21] M. Bäckström and G. Marquis, "A review of multiaxial fatigue of weldments: experimental results, design code and critical plane approaches," Fatigue \& Fracture of Engineering Materials \& Structures, vol. 24, no. 5, pp. 279-291, 2001.

[22] D. Radaj, C. Sonsino, and W. Fricke, Fatigue Assessment of Welded Joints by Local Approaches, CRC Press, 2nd edition, 2006.

[23] W. Qu, E. Zhao, and Q. Zhou, "Multiaxial cycle deformation and low-cycle fatigue behavior of mild carbon steel and related welded-metal specimen," Advances in Materials Science and Engineering, vol. 2017, Article ID 8987376, 2017.

[24] X. Chen, K. An, and K. S. Kim, "Low-cycle fatigue of $1 \mathrm{Cr}-18 \mathrm{Ni}$ 9Ti stainless steel and related weld metal under axial, torsional and $90^{\circ}$ out-of-phase loading," Fatigue \& Fracture of Engineering Materials \& Structures, vol. 27, no. 6, pp. 439-448, 2004.

[25] Y. Wang, X. Liu, G. Dai, and Y. Shi, "Experimental study on constitutive relation of steel SN490B under cyclic loading," Journal of Building Structures, vol. 35, no. 4, pp. 142-148, 2014.

[26] N. Shamsaei and A. Fatemi, "Effect of microstructure and hardness on non-proportional cyclic hardening coefficient and 
predictions," Materials Science and Engineering: A Structural Materials: Properties, Microstructure and Processing, vol. 527, no. 12, pp. 3015-3024, 2010.

[27] Z.-R. Wu, X.-T. Hu, and Y.-D. Song, "Multiaxial fatigue life prediction for titanium alloy TC4 under proportional and nonproportional loading," International Journal of Fatigue, vol. 59, pp. 170-175, 2014. 


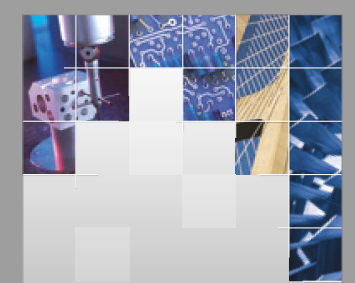

\section{Enfincering}
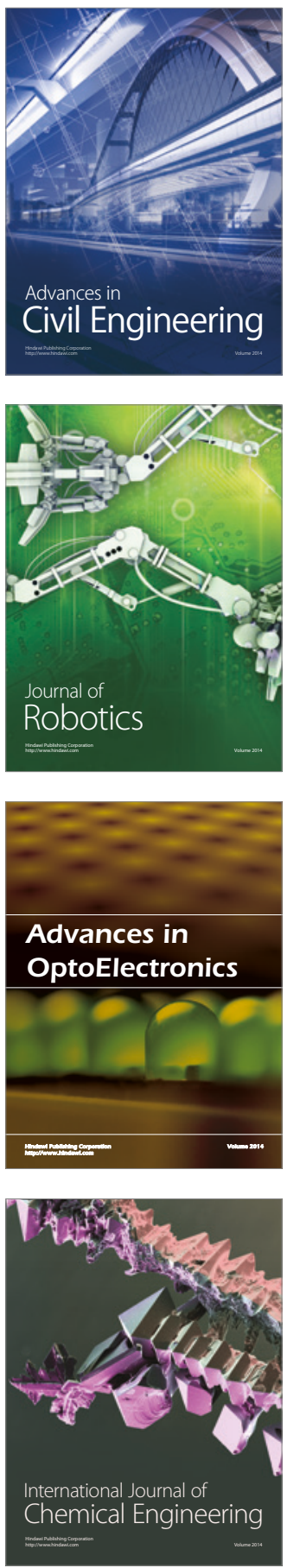

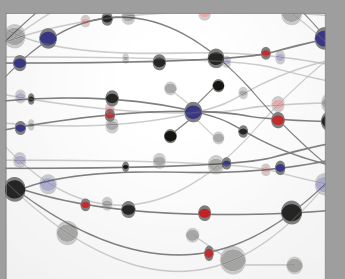

The Scientific World Journal

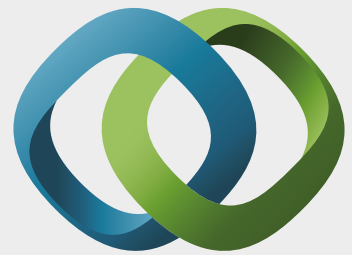

\section{Hindawi}

Submit your manuscripts at

https://www.hindawi.com
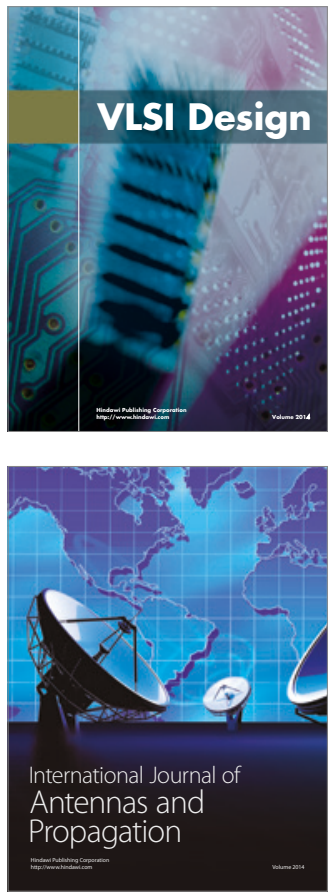

\section{Rotating}

Machinery
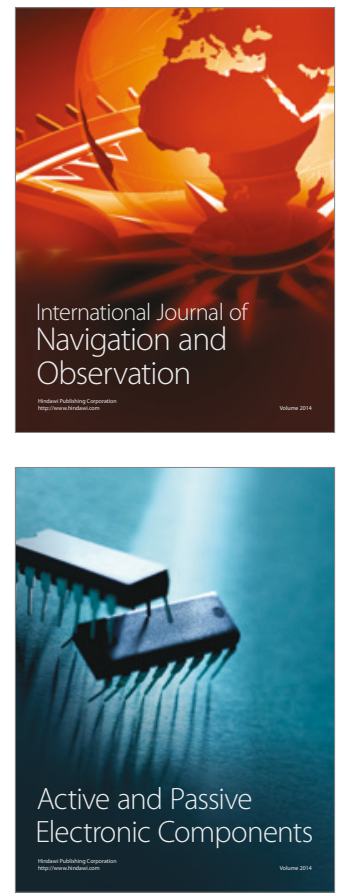
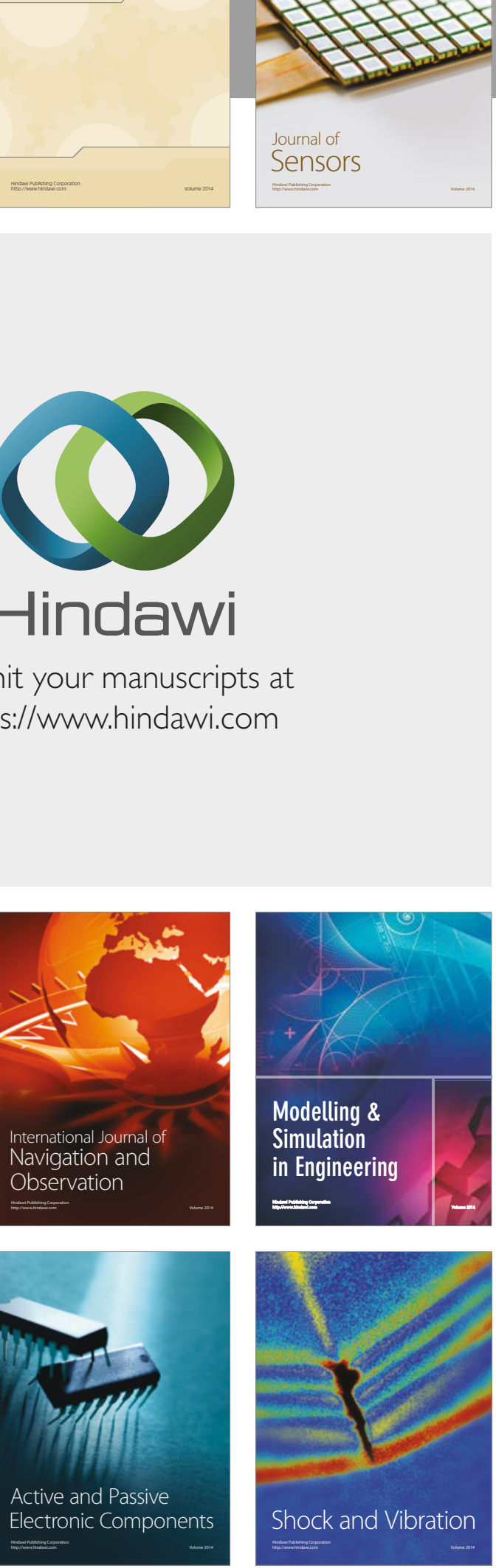
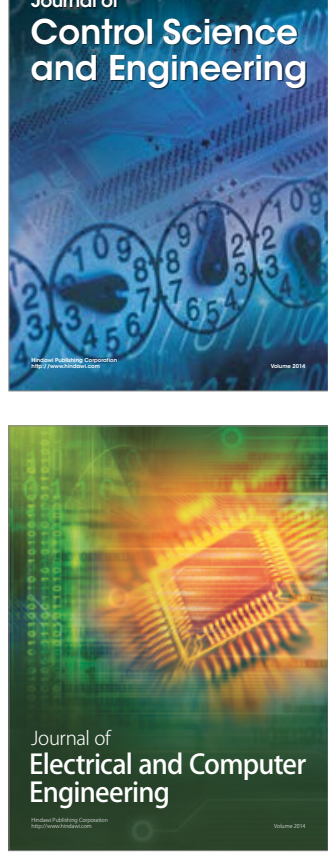

Distributed

Journal of

Control Science

and Engineering
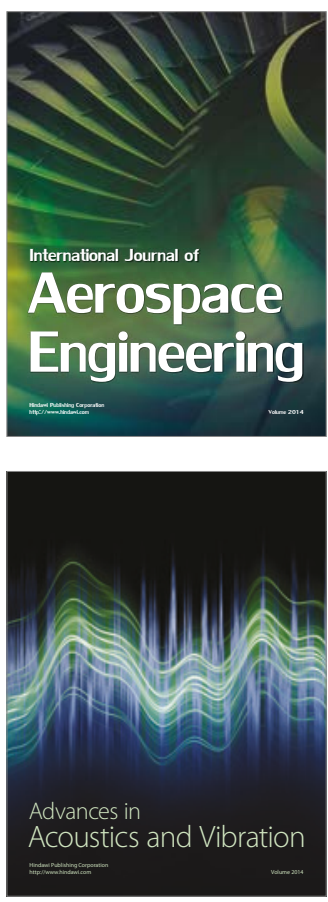

Sensor Networks 